\title{
The Optimal Arterial Access for Coronary Angiography: Femoral Route versus the Radial Route
}

Rashid $\mathbf{S}^{1 *}$ and Sawh $\mathbf{C}^{2}$

${ }^{1}$ Leeds General Infirmary, Great George Street, Leeds, West Yorkshire, LS1 3EX, UK

${ }^{2}$ Northern General Hospital, Herries Road, Sheffield, South Yorkshire, S5 7AU, UK

\begin{abstract}
The radial or femoral route is commonly used to access the coronary circulation for diagnostic coronary angiography or percutaneous coronary intervention. The radial route has been shown to be superior to the femoral route due to lower procedural costs, quicker recovery times and early discharge from hospital. Furthermore it is beneficial for patients who have back problems and are unable to lie flat for prolonged periods of time which is often the case with the femoral route. Several studies have highlighted lower vascular access complications and bleeding events from the radial route. Bleeding in itself is associated with adverse outcomes therefore by electing to perform coronary procedures by the radial route avoids such complications.
\end{abstract}

Keywords: Percutaneous coronary intervention; Coronary intervention; Vascular access

\section{Introduction}

Access to the coronary circulation for angiography or percutaneous coronary intervention is routinely performed by the radial or femoral route. Several trials have demonstrated a reduction in the bleeding rates with the radial route when compared to the femoral route. Bleeding is associated with adverse outcomes therefore the choice of vascular access is of paramount. Several factors are taken into consideration when deciding on the vascular access route. According to the European Society of Cardiology 2014 guidelines on myocardial revascularisation, the radial route should be preferred over the femoral route if the operator is able to perform the procedure by the radial route (class IIa recommendation) [1].

\section{Discussion}

Access to the coronary circulation can be achieved by either the radial, brachial or femoral route. The brachial route is rarely used. Coronary angiography via the radial approach was first reported in 1989 and its use for percutaneous coronary intervention was recognised in 1993. The radial route is widely adopted in most European countries, Asia and Canada but the uptake is slow in the United States and Germany [2].

The choice of vascular access is influenced by numerous factors. The operators experience and confidence in the use of the radial and femoral route is key to the decision making. The radial route is often technically more challenging than the femoral route and requires a steep learning curve. The patient's preference for vascular access is taken into consideration and is discussed with the patient when consenting for invasive coronary procedures.

The femoral artery is the choice of access when there is a weak or non palpable radial arterial pulse or there have been previous challenges with radial access due to extensive spasm or tortuosity of the artery.

The type of percutaneous coronary intervention to be performed influences the vascular access route chosen. Procedures such as rotablation to the coronary arteries or complex coronary bifurcation lesions require bigger sheaths and the femoral route is accommodating for this. Furthermore coronary artery bypass grafts are often much easy to engage via the femoral route. If the femoral vein needs to be accessed at the same time as the arterial circulation then the femoral route is often preferred as they are both in the same region. Examples would include patients who require dual assessment of right and left heart pressures in the presence of valvular heart disease to aid in diagnosis and management. Additionally the femoral route is accessed in patients who require coronary intervention and central venous access for drug administration or temporary wire insertion.

In patients who have end stage renal disease with arteriovenous fistulas for haemodialysis, coronary procedures are performed from the femoral route even when the opposite radial artery has not been intervened on as this needs to be preserved for future arteriovenous fistulas if required. Harvesting of the radial artery for coronary artery bypass grafting or scarring of the radial access site due to multiple arterial line insertions may persuade the operator to choose the femoral route.

Results from 4 large trials have consistently shown that cross over from the radial route to the femoral route occurs more frequently; $6.3 \%$ radially versus $1.7 \%$ for the femoral route [3]. This is due to anatomical differences with the radial artery being much smaller than the femoral artery, frequent spasm and tortuosity.

There is also reduced levels of contrast, shorter procedural times and less radiation exposure with the femoral route [4,5]. This should be taken into consideration for patients who have a degree of renal impairment where the volume of contrast needs to be limited to prevent contrast nephropathy.

On the contrary the radial access route is cheaper and enables patients to mobilise quicker without the need of a hospital bed [5-7]. This is particularly beneficial for patients who have back problems

*Corresponding author: Rashid S, Leeds General Infirmary, Great George Street, Leeds, West Yorkshire, LS1 3EX, UK, Tel: 0113 2432799; E-mail: shabnamrashid@doctors.org.uk

Received May 31, 2016; Accepted June 14, 2016; Published June 21, 2016

Citation: Rashid S, Sawh C (2016) The Optimal Arterial Access for Coronary Angiography: Femoral Route versus the Radial Route. J Vasc Med Surg 4: 271. doi:10.4172/2329-6925.1000271

Copyright: $\odot 2016$ Rashid S, et al. This is an open-access article distributed unde the terms of the Creative Commons Attribution License, which permits unrestricted use, distribution, and reproduction in any medium, provided the original author and source are credited. 
and are unable to lie flat for several hours which is often the case if the femoral route is accessed. Furthermore the duration of in hospital stay is shorter for patients having procedures performed via the radial route $[6,8,9]$ which subsequently reduces hospital costs. The delay in discharge is often attributed due to femoral access related complications. These patients often need bed rest, observation or even invasive treatment.

Femoral complications are also more likely in patients who have peripheral vascular disease or calcified peripheral arteries. The presence of peripheral vascular disease can make catheter manipulation difficult and haemostasis can be difficult to achieve post procedure. In these patients vascular access via the radial artery is desirable. Certain medications such as anti- platelets and antithrombotic agents predispose patients to bleeding regardless of the vascular access route. These drugs are prescribed in the majority of patients diagnosed with an acute coronary syndrome (ACS) and it is these patients who require invasive coronary intervention. The radial artery is superficial and easily compressible allowing haemostasis which can be more difficult with the femoral route. Therefore, in these circumstances and particularly in patients who are on regular anticoagulants, vascular access should be considered from the radial route. There is also unlikely to be damage to adjacent structures in comparison to the femoral route. These features make the radial route more attractive for coronary intervention [10].

Vascular access complications are seen in between 5-20\% of patients undergoing percutaneous coronary intervention (Table 1). These tend to be higher with femoral cases as the artery is much larger and punctures made high above the femoral bifurcation i.e the inferior epigastric artery, or below the femoral bifurcation increases the likelihood of complications. Complications include haematomas, pseudoanneurysms and retroperitoneal haemorrhage. Large haematomas often delay hospital discharge. Pseudoanneurysms can be managed conservatively or may require ultrasound scan guided compression, thrombin injection or in rare cases surgical intervention. Retroperitoneal haemorrhage caused by femoral punctures that are high above the femoral bifurcation i.e the inferior epigastric artery may result in retroperitoneal haemorrhage. This can be life threatening and may require surgical intervention. These complications are exacerbated by the use of antiplatelet therapies and anticoagulants [11]. Such complications are very rarely encountered with the radial route and often do not require invasive treatments.

Multiple trials have demonstrated that the radial route is superior to the femoral route due to lower bleeding events and vascular access site complications [4-6,8,9]. Bleeding is associated with adverse outcomes including stroke and death [12]. The radial route for coronary angiography and percutaneous coronary intervention (PCI) has demonstrated a reduction in major bleeding by $72 \%$ when compared to the femoral route. There is also a reduction in the composite of death, myocardial infarction (MI) and stroke; $2.5 \%$ in radial route versus $3.8 \%$ in femoral cases. Length of hospital stay was significantly shorter by 0.4 days with the radial route. However, inability to cross the lesion with a wire, balloon or stent was prevalent in $4.7 \%$ of the radial cases and $3.4 \%$ of the femoral cases which was not significant [13].

Bleeding is one of the potential complications after primary PCI for ST segment myocardial elevation (STEMI) due to the use of antiplatelet and antithrombotic agents. A meta-analysis assessing the safety and efficacy of the radial route and femoral route during primary PCI for patients with STEMI showed that the radial route was superior to the femoral route with regards to mortality and major bleeding. Mortality rates were significantly lower in the radial access group at $2.7 \%$ versus $4.7 \%$ in the femoral group. Major bleeding was also lower in patients who had the procedure performed by the radial route. Stroke risk was similar in both groups. However procedure time was approximately 1.5 minutes longer in the radial access group [14]. The longer duration of the procedure is contributed by anatomical differences in the course

\begin{tabular}{|c|c|c|}
\hline Trial & Number of patients & Outcomes of trial \\
\hline Tempura [20] & 149 & $\begin{array}{l}\text { The success rate of reperfusion and the incidence of in-hospital major adverse cardiac events were similar in the radial } \\
\text { and femoral group. }\end{array}$ \\
\hline Farmi trial [5] & 114 & $\begin{array}{l}\text { Vascular access complication rates were significantly lower in the radial group when compared to the femoral group. There } \\
\text { was quicker ambulation with the radial route. Coronary angiography and fluoroscopy duration were significantly longer in } \\
\text { the radial group than in the femoral group. Length of hospital stay was similar between the two groups. }\end{array}$ \\
\hline Gan L et al. [6] & 195 & $\begin{array}{l}\text { Significant reduction in vascular access related complications in the radial group } 2.2 \% \text { vs. } 11.4 \% \text { in the femoral group. } \\
\text { Length of hospital stay was significantly lower in the radial group. }\end{array}$ \\
\hline Radiami [7] & 100 & $\begin{array}{l}\text { No significant differences between radial and femoral group with regards to fluoroscopy timing, volume of contrast and } \\
\text { total procedure time. No significant differences in major bleeding between the two groups. Time to ambulation in the radial } \\
\text { group was significantly shorter. }\end{array}$ \\
\hline Hou et al. [8] & 200 & $\begin{array}{l}\text { Lower vascular complications and reduced length of hospital stay in the radial access group. No differences between radial } \\
\text { and femoral group with regards to puncture time, cannulation time, reperfusion, procedural and fluroscopy time }(p>0.05) \text {. } \\
\text { No statistical difference in the incidence of major adverse cardiac events between the two groups ( }>0.05) \text {. }\end{array}$ \\
\hline Rival [4] & 7021 & $\begin{array}{l}\text { The rate of death, myocardial infarction, stroke and non-CABG-related major bleeding at } 30 \text { days was similar in both the } \\
\text { radial and femoral group. Patients in the femoral group had statistically higher rates of vascular access complications } \\
\text { compared to the radial group. }\end{array}$ \\
\hline Radiami II [21] & 108 & $\begin{array}{l}\text { There were no significant differences in the incidence of major adverse cardiac events or bleeding complications between } \\
\text { the radial and femoral group. }\end{array}$ \\
\hline Rifle-steacs [9] & 1001 & $\begin{array}{l}\text { Major adverse cardiac events at } 30 \text { days occurred in } 13.6 \% \text { in the radial arm and } 21.0 \% \text { in the femoral arm }(p=0.003) \text {. } \\
\text { There was significantly lower rates of cardiac mortality in the radial arm; } 5.2 \% \text { vs. } 9.2 \% \text { femoral, } p=0.020 \text {, bleeding; } 7.8 \% \\
\text { radial vs. } 12.2 \% \text { femoral, } p=0.026 \text {, and shorter hospital stay. }\end{array}$ \\
\hline Matrix [16] & 7021 & $\begin{array}{l}\text { The outcomes for the use of the femoral and radial route for STEMI and non ST elevation myocardial infarction patients } \\
\text { were analysed. There was a lower composite of death, MI, stroke and major bleeding in patients who had the procedure } \\
\text { performed radially when compared to the femoral route, but this effect was more pronounced in patients with STEMI rather } \\
\text { than in patients with NSTEMI. For STEMI patients the composite outcome was seen in } 2.7 \% \text { in the radial cases versus } \\
4.6 \% \text { in the femoral cases. }\end{array}$ \\
\hline Qin et al. [22] & 596 & $\begin{array}{l}\text { No significant difference in angiography, percutaneous coronary intervention and fluoroscopy timings with the radial and } \\
\text { femoral route. There was a significant reduction in the duration of hospitalisation with the radial route. There was a higher } \\
\text { incidence of femoral complications. }\end{array}$ \\
\hline
\end{tabular}

Table 1: Trials comparing the radial route with the femoral route in patients with acute coronary syndromes undergoing primary percutaneous coronary intervention. 
of the radial artery as well as engagement of the coronaries. Timely access to the coronary circulation during an STEMI is crucial to allow reperfusion of the myocardium [10]. Other trials have also demonstrated that the duration of coronary angiography and fluoroscopy timings to be longer with the radial route [5]. Further studies however have shown that there is no significant difference between the femoral and radial group with regards to cannulation of the coronaries and fluoroscopy timing $[7,8]$. It is important to note that the majority of these trials recruited low number of patients.

The MATRIX and the RIVAL trial have both provided compelling results regarding the superior efficacy of the radial route for PCI versus femoral route. The RIVAL study is the largest randomised trial comparing the radial route with the femoral route for PCI. In this trial 7021 patients with a diagnosis of ACS were randomised to the radial or femoral access route. There was no significant difference in the 30 day composite of death, MI, stroke or major bleeding with the radial and femoral route; $3.7 \%$ and $4 \%$ respectively. There was however significantly lower vascular complications with the radial route [15]. In the MATRIX study the same cohort of patients from the RIVAL trial were analysed. The outcomes for the use of the femoral and radial route for STEMI and non ST elevation myocardial infarction (NSTEMI) patients were analysed. There was a lower composite of death, MI, stroke and major bleeding in patients who had the procedure performed radially when compared to the femoral route, but this effect was more pronounced in patients with STEMI rather than in patients with NSTEMI. For STEMI patients the composite outcome was seen in $2.7 \%$ in the radial cases versus $4.6 \%$ in the femoral cases [16]. It is important to note that patients with STEMI are often treated with multiple anti platelets and anti thrombotics therefore predisposing them to higher bleeding events. Therefore in this scenario the use of the radial route would be optimal to reduce bleeding events.

In the RIFLE-ACS 1001 patients with STEMI were randomised to the radial or femoral route during PCI. Bleeding and mortality rates were significantly lower in patients who had PCI performed via the radial route. Bleeding due to access site complications was $12.2 \%$ in the femoral cases and $7.8 \%$ in the radial cases [9].

A recent meta-analysis of over 8000 patients who were randomised to the radial or femoral route during an ACS found that there was a significant reduction in major bleeds, death, MI, stroke and all cause mortality with the radial route; $1.6 \%$ versus $2.2 \%$ femoral [17]. Given the evidence, the European Society of Cardiology 2014 guidelines on myocardial revascularisation states that the radial route should be preferred over the femoral route if the operator is able to perform the procedure by the radial route (class IIa recommendation) [1].

Intraaortic balloon pumps (IABP) are often used to support the patient's hemodynamics during PCI although there is no real evidence to support the use of IABP during cardiogenic shock. IABP are available in various sizes and are usually $7.5 \mathrm{Fch}$. The RADIAL PUMP UP registry demonstrated that IABP insertion via the radial route was better than the femoral route due to the lower rates of adverse outcomes. A 30 day composite of post-procedural bleeding, cardiac death, MI, target vessel revascularisation and stroke was apparent in $54.7 \%$ of patients who had IABP inserted via the femoral route and $36.6 \%$ in the radial group. The outcomes were mainly driven by access related bleeding from the femoral route [18]. Further studies are required to support the above findings as these patients were high risk patients and may have had other confounders affecting reported outcomes.

The radial route has been shown to be safe in patients who are having a diagnostic angiogram, PCI or IABP insertion. Conventionally the right radial artery tends to be used rather than the left due to the equipment set up in the catheterisation laboratory and ease for the operator. It is unclear as to whether the right radial artery (RRA) should be used or the left radial artery (LRA) for coronary angiography/PCI. A recent meta-analysis of 6870 patients undergoing angiography demonstrated that the LRA was superior to the RRA as there was a reduction in the contrast load, fluroscopy timing and less tortuosity. However more catheters were utilised with the LRA when compared to the right. Overall the LRA approach was found to be as safe as the RRA approach [19-22].

\section{Conclusion}

Access to the coronary circulation can be achieved by the radial and femoral route. Bleeding is associated with adverse outcomes and is more commonly seen in patients with acute coronary syndromes undergoing percutaneous coronary intervention due to the use of potent anti platelets and anti thrombotic agents. Several trials in such patients have demonstrated the superiority of the radial route over the femoral route as there is a significant reduction in bleeding events, death, myocardial infarction and stroke. However, each case needs to be individualised and in certain circumstances the femoral route is the optimal site of access if operators lack experience with the radial route or if there is radial arterial spasm or tortuosity.

\section{References}

1. Windercker S, Kohl P Alfonso F Collet JP Cremer J et al (2014) ESC/EACTS Guidelines on myocardial revascularization: The Task Force on Myocardial Revascularization of the European Society of Cardiology (ESC) and the European Association for Cardio-Thoracic Surgery (EACTS). European Heart Journal 35: 2541-2619.

2. Noble S (2016) Radial Access in Patients Invasively Treated for Acute Coronary Syndromes: A Lifesaving Approach. JACC Cardiovasc Interv 9: 671-673.

3. Andò G, Capodanno D (2015) Radial Versus Femoral Access in Invasively Managed Patients With Acute Coronary Syndrome: A Systematic Review and Meta-analysis. Ann Intern Med 163: 932-940.

4. Jolly SS, Yusuf S, Cairns J, Niemelä K, Xavier D, et al. (2011) Radial versus femoral access for coronary angiography and intervention in patients with acute coronary syndromes (RIVAL): a randomised, parallel group, multicentre trial. Lancet 377: 1409-1420.

5. Brasselet C, Tassan S, Nazeyrollas P, Hamon M, Metz D (2007) Randomised comparison of femoral versus radial approach for percutaneous coronary intervention using abciximab in acute myocardial infarction: results of the FARMI trial. Heart 93: 1556-1561.

6. Gan L, Lib Q, Liuc R, Zhaoc Y, Qiuc J, et al. (2009) Effectiveness and feasibility of transradial approaches for primary percutaneous coronary intervention in patients with acute myocardial infarction. Journal of Nanjing Medical University 23: $270-274$.

7. Chodor P, Krupa H, Kurek T, Sokal A, Swierad M, et al. (2009) RADlal versus femoral approach for percutaneous coronary interventions in patients with Acute Myocardial Infarction (RADIAMI): A prospective, randomized, singlecenter clinical trial. Cardiology Journal 16: 332-340.

8. Hou L, Wei YD, Li WM, Xu YW (2010) Comparative study on transradial versus transfemoral approach for primary percutaneous coronary intervention in Chinese patients with acute myocardial infarction. Saudi Medical Journal 31 158-162.

9. Romagnoli E, Biondi-Zoccai G, Sciahbasi A, Politi L, Rigattieri S, et al. (2012) Radial versus femoral randomized investigation in ST-segment elevation acute coronary syndrome: the RIFLE-STEACS (Radial Versus Femoral Randomized Investigation in ST-Elevation Acute Coronary Syndrome) study. J Am Coll Cardiol 60: 2481-2489.

10. Rao SV, Cohen MG, Kandzari DE, Bertrand OF, Gilchrist IC (2010) The transradial approach to percutaneous coronary intervention: historical perspective, current concepts, and future directions. J Am Coll Cardiol 55 2187-2195. 
Citation: Rashid S, Sawh C (2016) The Optimal Arterial Access for Coronary Angiography: Femoral Route versus the Radial Route. J Vasc Med Surg 4: 271. doi:10.4172/2329-6925.1000271

11. Merriweather N, Sulzbach-Hoke LM (2012) Managing Risk of Complications at Femoral Vascular Access Sites in Percutaneous Coronary Intervention. Critical CareNurse 32: 16-29.

12. Ndrepepa G, Berger PB, Mehilli J (2008) Periprocedural bleeding and 1-year outcome after percutaneous coronary interventions: appropriateness of including bleeding as a component of a quadruple endpoint. J Am Coll Cardiol 51: 690-6097.

13. Jolly SS, Amlani S, Hamon M, Yusuf S, Mehta SR (2009) Radial versus femoral access for coronary angiography or intervention and the impact on major bleeding and ischemic events: a systematic review and meta-analysis of randomized trials. Am Heart J 157: 132-140.

14. Karrowni W, Vyas A, Giacomino B, Schweizer M, Blevins A, et al. (2013) Radia versus femoral access for primary percutaneous interventions in ST-segment elevation myocardial infarction patients. A meta-analysis of randomized Controlled Trials. J Am Coll Cardiol Intv 6: 814-823.

15. Jolly SS, Niemelä K, Xavier D, Widimsky P, Budaj A, et al. (2011) Design and rationale of the radial versus femoral access for coronary intervention (RIVAL) trial: a randomized comparison of radial versus femoral access for coronary angiography or intervention in patients with acute coronary syndromes. Am Heart J 161: 254-260.

16. Mehta SR, Jolly SS, Cairns J, Niemela K, Rao SV, et al. (2012) Effects of radial versus femoral artery access in patients with acute coronary syndromes with or without ST-segment elevation. J Am Coll Cardiol 60: 2490-2499.
17. Valgimigli M, Gagnor A, Calabro P, Frigoli E, Leonardi S, et al. (2015) Radial versus femoral access in patients with acute coronary syndromes undergoing invasive management: a randomised multicentre trial. Lancet 385: 2465-2476.

18. Romagnoli E, De Vita M, Burzotta F, Cortese B, Biondi-Zoccai G, et al (2013) Radial versus femoral approach comparison in percutaneous coronary intervention with intraaortic balloon pump support: the RADIAL PUMP UP registry. Am Heart J 166: 1019-1026.

19. Xia SL, Zhang XB, Zhou JS, Gao X (2015) Comparative efficacy and safety of the left versus right radial approach for percutaneous coronary procedures: a meta-analysis including 6870 patients. Braz J Med Biol Res 48: 743-750.

20. Saito S, Tanaka S, Hiroe Y, Miyashita Y, Takahashi S, et al. (2003) Comparative study on transradial approach vs. transfemoral approach in primary stent implantation for patients with acute myocardial infarction: results of the test for myocardial infarction by prospective unicenter randomization for access sites (TEMPURA) trial. Cathetarization and cardiovascular interventions 59: 26-33.

21. Chodór $P$, Kurek T, Kowalczuk A, Swierad M, Was T, et al. (2011) Radial vs femoral approach with Star Close clip placement for primary percutaneous coronary intervention in patients with ST elevation myocardial infarction. RADIAMI II: A prospective, randomised, single centre trial. Kardiologia Polska 69: 763- 771.

22. Qin X, Xiong W, Wang L, Guan E, Lu C (2013) Clinical investigation of transradial access for emergent percutaneous coronary intervention in patients with acute myocardial infarction. Clin Interv Aging 8: 1139-1142. 